\title{
Erratum to: Heat transfer analysis in a Maxwell fluid over an oscillating vertical plate using fractional Caputo-Fabrizio derivatives
}

The Publishers

Società Italiana di Fisica and Springer-Verlag GmbH Germany, part of Springer Nature

Original article: Eur. Phys. J. Plus (2017) 132: 194, https://doi.org/10.1140/epjp/i2017-11456-2

Received: 3 February 2019

Published online: 11 March 2019

(C) Società Italiana di Fisica / Springer-Verlag GmbH Germany, part of Springer Nature, 2019

It came to the attention of the Publishers that the copyright holder of fig. 1 in the above-mentioned paper was not properly acknowledged.

Figure 1 was taken from fig. 9.3 on p. 596 of:

Theodore L. Bergman, Adrienne S. Lavine, Frank P. Incropera, David P. DeWitt, Fundamentals of Heat and Mass Transfer, 7th edition (John Wiley \& Sons, 2011) ISBN 13: 9780470501979 (978-0-470-50197-9) and is reproduced with kind permission of the publisher, John Wiley and Sons.

The Publishers regret this mistake and apologize for any inconvenience caused. 